\title{
Continuous Inhalation of Nitric Oxide Protects against Development of Pulmonary Hypertension in Chronically Hypoxic Rats
}

\author{
Christian Kouyoumdjian, * Serge Adnot, * Micheline Levame, * Saadia Eddahibi, * Hassan Bousbaa, * \\ and Bernadette Raffestin* \\ * Département de Physiologie, INSERM U 296, Hôpital Henri Mondor, 94010 Créteil, France; and ${ }^{\ddagger}$ Département de Physiologie, \\ Unité d'Enseignement et de Recherche Paris Ouest, Hôpital Ambroise Paré, 92100 Boulogne, France
}

\begin{abstract}
Exposure to hypoxia and subsequent development of pulmonary hypertension is associated with an impairment of the nitric oxide (NO) mediated response to endothelium-dependent vasodilators. Inhaled NO may reach resistive pulmonary vessels through an abluminal route. The aim of this study was to investigate if continuous inhalation of NO would attenuate the development of pulmonary hypertension in rats exposed to chronic hypoxia.

In conscious rats previously exposed to $10 \% \mathrm{O}_{2}$ for 3 wk, short-term inhalation of NO caused a dose-dependent decrease in pulmonary artery pressure (PAP) from $44 \pm 1$ to $32 \pm 1 \mathrm{mmHg}$ at $40 \mathrm{ppm}$ with no changes in systemic arterial pressure, cardiac output, or heart rate. In normoxic rats, acute NO inhalation did not cause changes in PAP. In rats simultaneously exposed to $10 \% \mathrm{O}_{2}$ and $10 \mathrm{ppm}$ NO during 2 wk, right ventricular hypertrophy was less severe $(P<0.01)$, and the degree of muscularization of pulmonary vessels at both alveolar duct and alveolar wall levels was lower $(P<0.01)$ than in rats exposed to hypoxia alone. Tolerance to the pulmonary vasodilator effect of NO did not develop after prolonged inhalation. Brief discontinuation of NO after 2 wk of hypoxia plus NO caused a rapid increase in PAP. These data demonstrate that prolonged inhalation of low concentrations of NO induces sustained pulmonary vasodilation and reduces pulmonary vascular remodeling in response to chronic hypoxia. (J. Clin. Invest. 1994. 94:578584.) Key words: endothelium-derived relaxing factor • chronic hypoxia • pulmonary circulation • vascular remodeling • ventricular hypertrophy
\end{abstract}

\section{Introduction}

There is growing evidence that the endothelium plays an important role in the regulation of vascular tone and also participates in the pathological processes of vascular remodeling. En-

Portions of this work were presented in abstract form (1992. FASEB [Fed. Am. Soc. Exp. Biol.] J. 6:A1178).

Address correspondence to Dr. Serge Adnot, Service des Explorations Fonctionnelles, Hôpital Henri Mondor, 94010 Créteil, France.

Received for publication 15 January 1993 and in revised form 5 January 1994

J. Clin. Invest

(C) The American Society for Clinical Investigation, Inc.

0021-9738/94/08/0578/07 \$2.00

Volume 94, August 1994, 578-584 dothelium-derived relaxing factor (EDRF),${ }^{1}$ now identified as nitric oxide (NO) or an NO-related substance $(1,2)$, is a powerful vasodilator (3). Previous studies suggest that NO may also cause inhibition of smooth muscle proliferation $(4,5)$. The endothelium appears to be functionally abnormal in various vascular diseases. Indeed, impaired endothelium-dependent relaxant activity has been demonstrated in experimental and human diseases such as hypercholesterolemia (6), atherosclerosis (7), systemic hypertension (8), and chronic hypoxic pulmonary hypertension (9). Therefore, the inability of the endothelial cells to produce NO may lead not only to inappropriate vasoconstrictor responses to various stimuli but also to the loss of one of the mechanisms that maintains smooth muscle cells quiescent in the vascular wall.

Chronic hypoxic pulmonary hypertension, which is the consequence of increased smooth muscle tone and structural remodeling of the pulmonary arteries, is associated with alterations in endothelium-dependent relaxant activity. Responses to the endothelium-dependent vasodilator substances, acetylcholine and the calcium ionophore A23187, are impaired in the lungs (9) and isolated arteries (10) of rats previously exposed to chronic hypoxia. Endothelium-dependent relaxation to acetylcholine and ADP is also impaired in isolated pulmonary arteries obtained from hypoxic patients suffering from severe chronic obstructive lung disease (11). However, other studies suggest persistence of endogenous NO formation during chronic hypoxia $(12,13)$ but apparently not at a level sufficient to prevent development of pulmonary hypertension. In the present study, we questioned whether administration of exogenous NO would attenuate structural remodeling of the pulmonary arteries in response to chronic hypoxia. Recent data have shown that inhaled NO, which reaches the pulmonary vessels through an abluminal route, may induce potent pulmonary vasodilation. Since NO reaching the blood is rapidly inactivated by combining with hemoglobin, vasodilation is restricted to the pulmonary vascular bed with no changes in systemic arterial tone. Indeed, in sheep (14) and humans exposed to acute hypoxia (15), inhalation of NO is associated with a dose-dependent selective pulmonary vasodilator effect. In patients with primary pulmonary hypertension, inhaling NO in a concentration of $40 \mathrm{ppm}$ produces pulmonary vasodilation equivalent to that produced by prostacyclin (16). Trials of prolonged NO inhalation have also been reported in the newborn with persistent pulmonary hypertension $(17,18)$ and adults with respiratory distress syndrome (19).

In the first part of this study, we examined the hemodynamic effects of short-term inhalation of NO at various concentrations

1. Abbreviations used in this paper: $\mathrm{CO}$, cardiac output; EDRF, endothelium-derived relaxing factor; NO, nitric oxide; PAP, pulmonary artery pressure; SAP, systemic artery pressure. 
in chronically hypoxic rats and assessed the lowest concentration at which inhaled NO exerts a significant pulmonary vasodilator effect. In the second part of the study, we investigated whether continuous NO inhalation at this low concentration during a 2-wk exposure to hypoxia might attenuate the development of pulmonary hypertension and lessen the severity of vascular remodeling and right ventricular hypertrophy.

\section{Methods}

\section{Acute hemodynamic effects of NO inhalation after chronic exposure to hypoxia}

Chronic hypoxia. Male Wistar rats, weighing 250-300 g at the start of the experiment, were exposed for $3 \mathrm{wk}$ to chronic hypoxia (10-12\%) in a ventilated chamber (500-liter volume; Flufrance, Cachan, France) as described previously (9). To establish the hypoxic environment, the chamber was flushed with a mixture of room air and nitrogen, and the gas was recirculated. The chamber environment was monitored with an oxygen analyzer (model OA150; Servomex, Crowborough, United Kingdom). Carbon dioxide was removed by soda lime granules, and excess humidity was prevented by cooling of the recirculation circuit. The chamber temperature remained at $22-24^{\circ} \mathrm{C}$. The chamber was opened every other day for $2 \mathrm{~h}$ to clean the cages and replenish food and water. Normoxic rats were kept in the same room, with the same light-dark cycle. Rat chow and tap water were provided ad libitum.

Hemodynamic measurements in conscious rats. At the end of the third week of exposure, five hypoxic and five normoxic rats were anesthetized with an intramuscular injection of ketamine $(20 \mathrm{mg})$ and xylazine $(1 \mathrm{mg})$. The right jugular vein was exposed, and a polyvinyl catheter was inserted and manipulated through the right ventricle into the pulmonary artery. The location of the catheter was assessed from the shape of the pressure tracing. A polyethylene catheter (PE50) was inserted into the right carotid artery. A silastic catheter was inserted into the left jugular vein for the return of blood to the rat during subsequent cardiac output measurements. A second polyvinyl catheter was also inserted into the left jugular vein to allow injection of indocyanine green dye. The catheters were filled with heparinized saline, sealed, and tunneled under the skin to the back of the neck, where they were exteriorized, secured, and protected in a small plastic container. Chronically hypoxic rats were returned to the hypoxic chamber after recovery from anesthesia.

Measurements were taken $1 \mathrm{~d}$ after surgery with the rat awake breathing the same gas mixture to which it had been chronically exposed. Thus, rats exposed to chronic hypoxia were placed in a small Plexiglas box flushed with $10 \% \mathrm{O}_{2}$ and $90 \% \mathrm{~N}_{2}$, and the normoxic rats were studied in the same Plexiglas box flushed with room air. Pulmonary artery (PAP) and systemic artery pressure (SAP) were measured using Gould P 23 ID transducers, coupled to pressure modules and a Gould TA 550 multichannel recorder (Gould, Ballainvilliers, France). Heart rate was computed from the SAP recording. Cardiac output was measured using a dye dilution technique. A $50-\mu \mathrm{g}$ bolus of indocyanine $(1 \mathrm{mg} / \mathrm{ml})$ was injected into the jugular vein. Blood $(1 \mathrm{ml} / \mathrm{min})$ was withdrawn from the carotid artery through a densitometer cuvette (Waters Instruments, Inc., Rochester, $\mathrm{MN}$ ) and returned to the rat through the left jugular vein. Cardiac output ( $\mathrm{CO}$ ) was calculated from the dye dilution curve area after exponential extrapolation of the downslope. Calibration was performed at the end of each study with a known concentration of green dye $(5 \mu \mathrm{g} / \mathrm{ml}$ rat blood $)$. Each $\mathrm{CO}$ value was the mean of at least three measurements. Total pulmonary resistance was calculated as mean PAP divided by CO. Total systemic vascular resistance was calculated as mean SAP divided by $\mathrm{CO}$.

NO (stored as $300 \mathrm{ppm}$ in pure $\mathrm{N}_{2}$; Compagnie Française des Produits Oxygénés, Meudon La Forêt, France) was added to the gas inlet of the Plexiglas box and diluted with the hypoxic (chronically hypoxic group) or normoxic (control normoxic group) gas mixture to obtain a given NO concentration. Precise flows were adjusted using flowmeters which were volumetrically calibrated before the study. The fractional concentration of $\mathrm{O}_{2}$ in the inspired gas was monitored continuously with an oxygen analyzer (Servomex) and maintained constant using an $\mathrm{O}_{2}$ blender. The NO concentration was increased at 6-min intervals from 0 to $5,10,20$, and $40 \mathrm{ppm}$. Mean PAP and SAP values were monitored continuously, and $\mathrm{CO}$ was measured before NO inhalation and in the last minute of the 40-ppm challenge. After discontinuation of NO and the return of PAP to baseline levels, a second exposure to $5 \mathrm{ppm}$ NO was performed for $15 \mathrm{~min}$.

\section{Continuous inhalation of NO during exposure to chronic hypoxia}

Experimental apparatus for chronic hypoxia. The rats were housed in two separate Plexiglas chambers (9-liter volume), each continuously flushed for $2 \mathrm{wk}$ with a mixture of room air and nitrogen at a constant flow rate of 4 liters $/ \mathrm{min}$. NO stored as $300 \mathrm{ppm}$ in pure $\mathrm{N}_{2}$ was added at a flow rate of 0.14 liters/min to the gas inlet of one chamber (hypoxic + NO group) and therefore diluted with the 4 liters/min of the hypoxic gas flushing this chamber. Pure $\mathrm{N}_{2}$ instead of $\mathrm{NO}$ in $\mathrm{N}_{2}(0.14$ liters/ min) was added to the gas inlet of the other chamber (hypoxic control group) to adjust the oxygen concentration to the same value (10\%) in both chambers. The environment within the two chambers was monitored with an oxygen analyzer. Soda lime granules were placed in the chambers to scavenge $\mathrm{NO}_{2}$ formed in the system. The gas flushing both chambers was not recirculated and was drained outdoors. A chemiluminescence $\mathrm{NO} / \mathrm{NO}_{2}$ analysis (Topaze 2020; Cosma SA, Igny, France) was performed at the inlet and the outlet of the hypoxic + NO chamber to assess $\mathrm{NO}$ and $\mathrm{NO}_{2}$ concentrations. NO concentration was $10 \pm 0.5$ $\mathrm{ppm}$, and $<0.5 \mathrm{ppm} \mathrm{NO}$ was detected at the inlet and outlet of the chamber. The chambers were opened every day for cleaning and to replenish food. The rats were divided randomly into two groups: one group $(n=14)$ was exposed to hypoxia $+10 \mathrm{ppm} \mathrm{NO}$; the other group $(n=12)$ was exposed to hypoxia alone.

Hemodynamic study and preparation of tissues for histological analysis. At the end of the second week of hypoxia, the rats were anesthetized with ketamine and xylazine. Immediately after the insertion of catheters in the pulmonary and carotid arteries, PAP and SAP were measured. At this time, rats were breathing room air spontaneously and for those previously exposed to NO, disconnected of NO. Blood was collected from the carotid artery for hematocrit and methemoglobine measurements. Blood methemoglobin was measured by spectrophotometry (model OSM3; Radiometer, Copenhagen, Denmark). Finally, after an intraperitoneal injection of sodium pentobarbital $(20 \mathrm{mg} / \mathrm{kg})$, the thorax was opened, and the heart was quickly removed, dissected, and weighed. The ratio of right ventricular free wall weight to the sum of septal plus left ventricular free wall weight (fresh tissue) was used as an index of right ventricular hypertrophy.

The lungs were fixed in the distended state by infusion of $4 \%$ phosphate-buffered formalin into the trachea at $25-\mathrm{cmH}_{2} \mathrm{O}$ pressure. The entire specimen was placed in a bath of the same fixative for a week. A midsaggital slice of the right lung, including the apical, azygous, and diaphragmatic lobes, was processed for paraffin embedding. Sections $5-\mu \mathrm{m}$ thick were cut for light microscopy and stained with hematoxylin phloxine saffron and orcein-picroindigo-carmine. In each rat, 35-65 intraacinar vessels, accompanying either alveolar duct or alveolus, were analyzed. Their type was identified as muscular, partially muscular, and nonmuscular. Muscularization was assessed by identification of typical cells stained red by phloxine with elongated shape and square ends nuclei, bound by two orcein-stained elastic lamina.

After similar preparation of the tissues, index of right ventricular hypertrophy and muscularization of distal vessels were also assessed in 15 control rats kept in normoxia (in each rat, 44-57 vessels were examined at either alveolar duct or alveolar wall level).

Acute hemodynamic effects of NO discontinuation in rats chronically exposed to hypoxia $+N O$ for $2 w k$. The acute hemodynamic consequences of NO discontinuation were examined in five rats previously exposed to hypoxia $+\mathrm{NO}$ for $2 \mathrm{wk}$ to assess the sustained effect of chronic NO inhalation on pulmonary vascular tone. At the end of the second week of exposure to hypoxia $+\mathrm{NO}$, rats were implanted with 

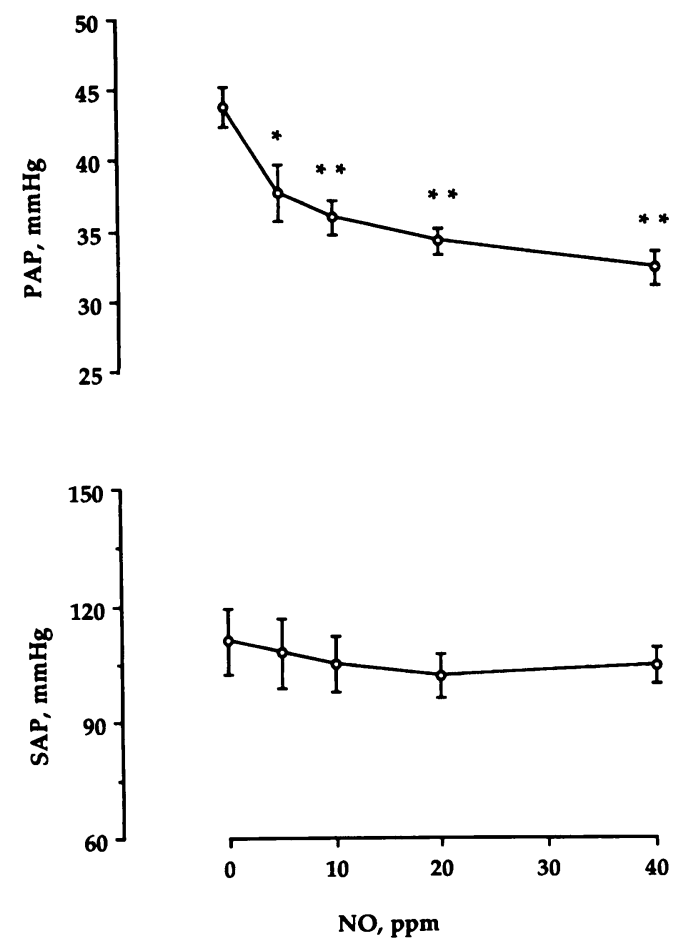

Figure 1. Effects of acute inhalation of NO on PAP and SAP in conscious rats previously exposed to $3 \mathrm{wk}$ of hypoxia $(n=5)$. The concentration of NO was increased at 6-min intervals. The results are expressed as means \pm SEM. $* P<0.05$ and $* * P<0.01$ compared with baseline values.

catheters, returned to hypoxia $+\mathrm{NO}$ after recovery from the anesthesia, and studied $24 \mathrm{~h}$ later in the conscious state. Hemodynamic measurements were performed with the rats breathing the same gas mixture to which they had been chronically exposed $\left(10 \% \mathrm{O}_{2}+10 \mathrm{ppm} \mathrm{NO}\right)$, then $\mathrm{NO}$ was discontinued for 45 min with $\mathrm{FIO}_{2}$ maintained at $10 \%$. Thereafter, a second NO challenge ( $10 \mathrm{ppm}$ for $15 \mathrm{~min}$ ) was performed. Mean PAP and SAP were monitored continuously, and $\mathrm{CO}$ was measured before, $45 \mathrm{~min}$ after NO discontinuation, and $15 \mathrm{~min}$ after reexposure to NO.

\section{Statistical analysis}

The results are expressed as means \pm SEM.

A two-way ANOVA was used to evaluate the hemodynamic effects of acute exposure to NO or NO discontinuation; the two factors in the analysis were time and animal. Comparisons between values at different times after exposure and baseline conditions were carried out with a modified $t$ test using residual value to compute the $t$ values.

A one-way ANOVA was performed after arc sine transformation of individual values for comparisons of ratio of right ventricle to left ventricle plus septum weight between hypoxic, hypoxic with continuous inhalation of NO, and normoxic groups (20). Since ANOVA indicated the significance of differences between groups, comparison between two groups was carried out with a modified $t$ test using the residual value to compute the $t$ values. To compare degree of muscularization of pulmonary vessels between hypoxic control, hypoxic with continuous inhalation of NO, and normoxic groups, vessels were ordinally classified as nonmuscular, partially muscular, and muscular. Comparison of muscularization was performed separately at the alveolar duct and alveolar wall levels by a nonparametric Kruskal-Wallis test. When a significant difference was observed, multiple pairwise comparisons were performed with the Scheffe method.

\section{Results}

Acute hemodynamic effects of NO inhalation. In conscious normoxic rats, PAP was $16.2 \pm 0.4 \mathrm{mmHg}$ and remained unchanged with acute NO inhalation up to the $40-\mathrm{ppm}$ concentration (15.5 $\pm 0.5 \mathrm{mmHg}$ ). SAP and $\mathrm{CO}$ also remained unchanged.

In conscious rats previously exposed to $3 \mathrm{wk}$ of hypoxia and studied in a hypoxic environment, acute NO inhalation induced a dose-dependent decrease in PAP (from 43.7 \pm 1.4 baseline to $32.2 \pm 1.2 \mathrm{mmHg}$ with $40 \mathrm{ppm} \mathrm{NO}$ ) while the heart rate and SAP remained unchanged (Fig. 1). $\mathrm{CO}$ measured at the highest NO concentration remained unaltered, as well as total systemic vascular resistance (Fig. 2). Total pulmonary vascular resistance decreased by $23 \pm 9 \%$ at $40 \mathrm{ppm}$ NO. When rats were exposed to $5 \mathrm{ppm}$ NO for $15 \mathrm{~min}$, PAP decreased from $43 \pm 3$ to $37 \pm 3 \mathrm{mmHg}$ within $2-3 \mathrm{~min}$ and plateaued out thereafter. $\mathrm{CO}$ remained unchanged. Discontinuation of NO was followed by a return of PAP to its hypertensive baseline value within 2-3 min.

Continuous inhalation of NO during chronic exposure to hypoxia. At the end of the second week of hypoxia, body weight $(275 \pm 5$ vs $286 \pm 5 \mathrm{~g})$ was similar in the group exposed to NO during hypoxia and the hypoxic control group. Hematocrit did not differ between the hypoxic plus NO and the hypoxic control groups ( $53 \pm 1$ vs $56 \pm 2 \%$ ) but was significantly higher than the value in the normoxic group $(42 \pm 0.7 \%)$. Hypoxic NO-treated and control hypoxic rats also did not differ with respect to heart rate $(345 \pm 14$ vs $372 \pm 34$ beats/min), SAP $(109 \pm 4$ vs $114 \pm 8$ $\mathrm{mmHg}$ ), and PAP ( $35 \pm 2$ vs $36 \pm 3 \mathrm{mmHg}$ ), these hemodynamics variables being measured $1 \mathrm{~h}$ after removal from the cham-
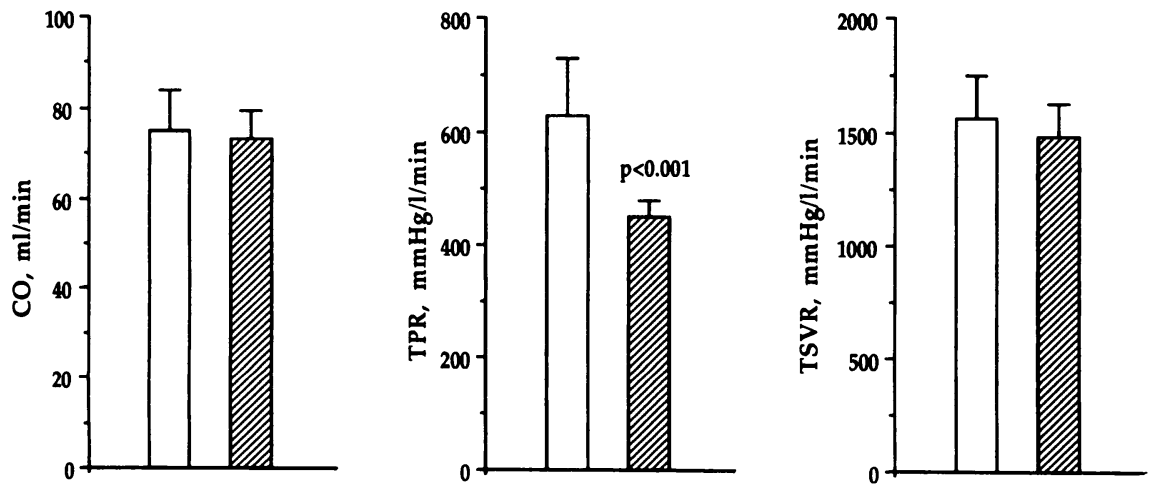

Figure 2. Bar graphs showing $\mathrm{CO}$, total pulmonary resistance $(T P R)$, and total systemic vascular resistance $(T S V R)$ in conscious rats previously exposed to $3 \mathrm{wk}$ of hypoxia ( $n$ $=5$ ) before (open bar) and during acute inhalation of $40 \mathrm{ppm}$ NO (hatched bar). The results are expressed as means \pm SEM. 


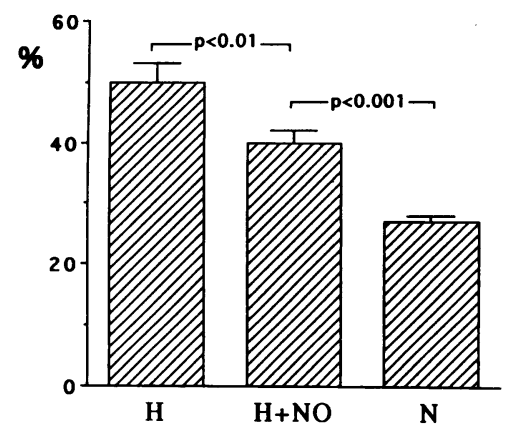

Figure 3. Ratio of right ventricle/left ventricle plus septum weight after a 2-wk exposure to $10 \%$ $\mathrm{O}_{2}(H, n=12), 10 \% \mathrm{O}_{2}$ $+10 \mathrm{ppm} \mathrm{NO}(H+N O$, $n=14)$, or normoxia $(N$, $n=15$ ). Results are expressed as means \pm SEM.

bers while the rats were anesthetized and breathing room air spontaneously. In contrast, right ventricular hypertrophy as assessed by the ratio of right ventricle to left ventricle plus septum weight was less severe in the hypoxic group continuously exposed to NO than in the hypoxic control group $(P<0.01)$. This ratio, however, remained significantly higher in the hypoxic NO-treated group than in the control normoxic group ( $P$ $<0.001$, Fig. 3 ). Continuous inhalation of NO also partially prevented muscularization of distal pulmonary arteries in response to hypoxia (Fig. 4). 644 vessels in the hypoxic NOtreated group and 538 vessels in the hypoxic group were examined. Distribution according to the accompanying airway (alveolar duct or alveolar wall) and degree of muscularization are given in Table I. Muscularization of the pulmonary vessels was significantly different in the three groups at alveolar duct $(P$ $<0.001)$ and alveolar wall levels $(P<0.001)$. The hypoxic NO-treated group had decreased muscularization of vessels at both alveolar duct and alveolar wall levels when compared with the hypoxic control group $(P<0.01)$. However, muscularization of vessels remained significantly increased in the hypoxic NO-treated group when compared with the normoxic group ( $P$ $<0.001$ ).

In five additional conscious rats, studied after 2 wk of hypoxia plus NO, PAP was $23.6 \pm 1.4 \mathrm{mmHg}$ during exposure to hypoxia plus NO and rose progressively during the $45 \mathrm{~min}$ of acute discontinuation of NO, whereas SAP remained unchanged (Fig. 5). $\mathrm{CO}$ also remained unchanged at $105 \pm 31 \mathrm{ml} / \mathrm{min}^{-1}$ before and $104 \pm 20 \mathrm{ml} / \mathrm{min}^{-1} 45 \mathrm{~min}$ after NO discontinuation. After reexposure to NO, PAP returned within $15 \mathrm{~min}$ to its value before NO discontinuation. In this additional group, ratio of right ventricle to left ventricle plus septum weight was $0.37 \pm 0.04$.
Table I. Distribution of Vessels According to Accompanying Airway

\begin{tabular}{lccc}
\hline & \multicolumn{3}{c}{ Group } \\
\cline { 2 - 4 } & $\begin{array}{c}\text { Hypoxia } \\
(n=12)\end{array}$ & $\begin{array}{c}\text { Hypoxia }+ \text { NO } \\
(n=14)\end{array}$ & $\begin{array}{c}\text { Normoxia } \\
(n=15)\end{array}$ \\
\hline \multicolumn{4}{c}{ Number (percent) } \\
Alveolar duct & & & \\
NM & $83(30.5)$ & $167(44.8)$ & $219(69.3)$ \\
PM & $102(37.5)$ & $132(35.4)$ & $81(25.6)$ \\
M & $87(32.0)$ & $74(19.8)$ & $16(5.1)$ \\
Total & 272 & 373 & 316 \\
Alveolar wall & & & $384(91.4)$ \\
NM & $138(51.9)$ & $174(64.2)$ & $29(6.9)$ \\
PM & $64(24.0)$ & $75(27.7)$ & $7(1.7)$ \\
M & $64(24.0)$ & $22(8.1)$ & 420 \\
Total & 266 & 271 & \\
& & &
\end{tabular}

Values are number of vessels counted per group according to accompanying airway structure and degree of muscularization. $N M$, nonmuscular; $P M$, partially muscular; $M$, muscular; $n=$ number of animals in each group. In rats simultaneously exposed to $10 \% \mathrm{O}_{2}$ and $10 \mathrm{ppm}$ NO during 2 wk (hypoxia + NO group), the degree of muscularization at either the alveolar duct or the alveolar wall level was less severe than in rats exposed to hypoxia alone (hypoxia group, $P<0.01$ ), but nevertheless increased when compared with normoxic rats (normoxia group, $P$ $<0.001$, nonparametric Kruskal-Wallis test followed by Scheffe test).

\section{Discussion}

This study shows that during exposure to chronic hypoxia, a condition associated with structural remodeling of pulmonary arteries, prolonged inhalation of low concentrations of NO has protective effects against the development of pulmonary hypertension. In rats exposed to hypoxia $\left(\mathrm{FIO}_{2} 10 \%\right)$ for $2 \mathrm{wk}$, continuous inhalation of $10 \mathrm{ppm}$ NO reduced right ventricular hypertrophy and the extension of muscularization in distal vessels.

The short-term effects of inhaled NO were assessed in conscious instrumented rats. Acute inhalation of NO induced potent and selective pulmonary vasodilation in rats previously exposed to $3 \mathrm{wk}$ of hypoxia and studied in a hypoxic environment. The vasodilator effect of NO occurred in a dose-dependent manner in response to concentrations varying from 5 to $40 \mathrm{ppm}$. Pulmonary vasodilation was rapid, maximal within 3-5 min, and was maintained throughout the inhalation period. Discontinuation of
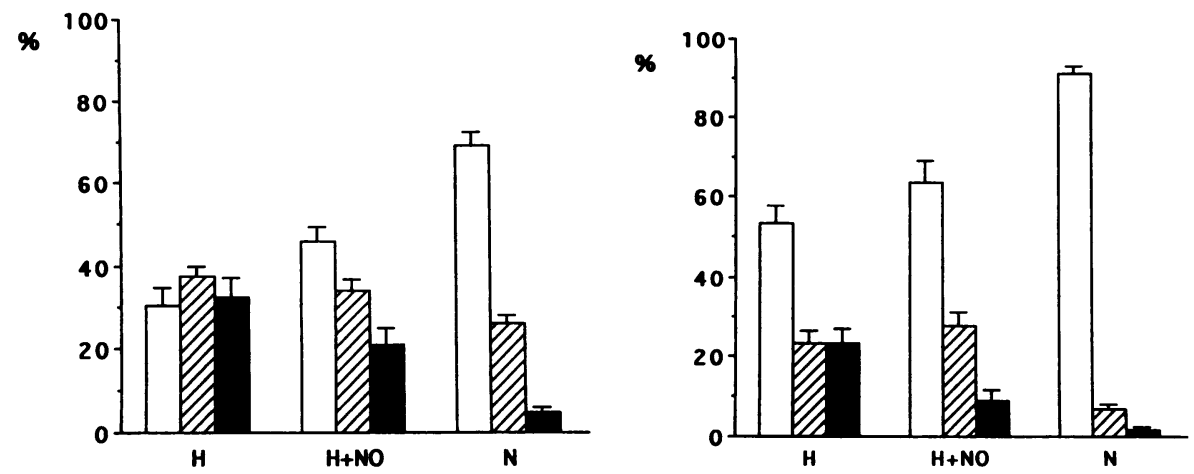

Figure 4. Bar graphs showing the percentage of muscularized (black bars), partially muscularized (hatched bars), and nonmuscularized (open bars) arteries at the alveolar duct and alveolar wall levels after a 2-wk exposure to $10 \% \mathrm{O}_{2}(H, n=12), 10 \% \mathrm{O}_{2}$ $+\mathrm{NO}(H+N O, n=14)$, or normoxia $(N$, $n=15)$. The results are expressed as means \pm SEM of the percentages assessed in each rat. In each animal, average number of analyzed vessels was 23 (range 15-41) at alveolar duct level and 23 (range 14-37) at alveolar wall level. 


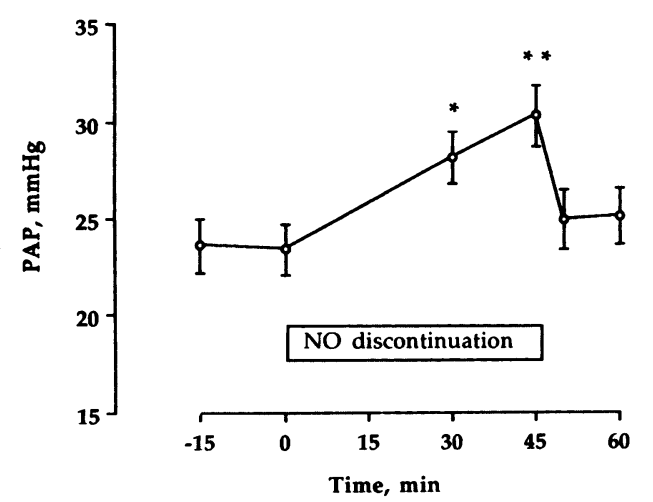

Figure 5. Effects of acute discontinuation of NO on PAP in five conscious rats previously exposed for 2 wk to $10 \% \mathrm{O}_{2}+10 \mathrm{ppm}$ NO. During the entire experiment, animals were breathing $10 \% \mathrm{FIO}_{2}$. The results are expressed as means \pm SEM. ${ }^{*} P<0.01$ and $* * P<0.001$ compared with baseline values before NO discontinuation.

NO inhalation was associated with a rapid rise in PAP which returned to its hypertensive baseline value within 2-3 min. These results are in accordance with previous studies examining the acute effects of NO inhalation in animals and humans with pulmonary hypertension. In conscious lambs, inhaled NO at $40 \mathrm{ppm}$ reverses acute pulmonary vasoconstriction induced by infusion of the endoperoxide analogue U46619, exposure to acute hypoxia (14), or heparin-protamine reaction (21). In these studies, breathing $80 \mathrm{ppm}$ NO for $1 \mathrm{~h}$ produces sustained pulmonary vasodilation without evidence of tolerance. In patients with primary pulmonary hypertension, NO inhalation (40 $\mathrm{ppm}$ ) causes a decrease in pulmonary vascular resistance similar to that observed after prostacyclin infusion (16). In patients with chronic obstructive lung disease, the pulmonary vasodilator response to NO was found to be greater than that induced by acetylcholine (22). In these previous studies, as in the present one, NO inhalation did not alter CO or SAP. Since NO reaching the blood is rapidly inactivated by combining with hemoglobin, the vasodilating effect of inhaled NO is selectively exerted on the pulmonary vasculature.

In contrast to chronically hypoxic rats, normoxic rats did not exhibit pulmonary vasodilation in response to inhaled NO. Similarly, Frostell et al. (14) did not observe any reduction of baseline normal PAP in sheep during NO inhalation. These results are consistent with the fact that the pulmonary vascular tone is elevated in rats with chronic hypoxic pulmonary hypertension but low in normoxic control animals. The role of endogenous NO in maintaining low vasomotor tone in normal pulmonary circulation is still uncertain. The observation that various $\mathrm{NO}$ antagonists enhance the pulmonary pressor response to acute hypoxia $(23,24)$ suggests that endogenous NO modulates pulmonary vascular tone and serves as a protective mechanism against pulmonary vasoconstriction. In a previous study, we found that chronic hypoxic pulmonary hypertension is associated with impaired endothelium-dependent relaxation (9). The vasodilator response to acetylcholine and ionophore A23187 is abolished, and the constrictor response to endothelin is potentiated in the isolated lung of rats exposed to chronic hypoxia. Therefore, impaired EDRF activity, while reducing the ability of the pulmonary vasculature to relax, also enhances the vasoconstrictor response to various stimuli. These functional abnormalities of the pulmonary vasculature are likely to be due to an impaired synthesis and/or release of NO by the endothelium. Indeed, pretreatment with L-arginine, the physiological precursor of NO (25), restores the vasodilator response to acetylcholine or ionophore A23187 and normalizes the vasoconstrictor response to endothelin-1 in the isolated lung of chronically hypoxic rats (26). However, these effects of $L$-arginine are only transient and are obtained with large doses of L-arginine.

The development and maintenance of pulmonary hypertension during chronic hypoxia is the result of increased vascular tone, polycythemia, and structural remodeling of pulmonary arteries (27-29). Continuous inhalation of NO during exposure to hypoxia attenuated right ventricular hypertrophy and reduced the ratio of right ventricle to left ventricle plus septum weight while it did not change the hematocrit. Since right ventricular hypertrophy is the consequence of sustained pulmonary hypertension, these results suggest that NO had a sustained lowering effect on pulmonary artery pressure. However, when measured at the end of the 2-wk exposure to hypoxia, PAP did not differ between the NO-treated and the control hypoxic groups. In both groups of chronically hypoxic rats, PAP was measured in anesthetized animals within $1 \mathrm{~h}$ of removal from the chamber. If continuous inhalation of NO exerts a braking effect on a constrictor mechanism, discontinuation of NO shortly before the measurement of PAP may have been followed by a rapid increase of tone. Indeed, in the few additional rats studied at the end of the 2-wk exposure to hypoxia plus NO, while conscious, hypoxic, and inhaling $10 \mathrm{ppm}$ NO, PAP was $~ 10 \mathrm{mmHg}$ lower than in animals from the same group studied anesthetized and breathing room air, but rose rapidly when NO was discontinued. Therefore, it is likely that an increase of PAP after NO discontinuation led to overestimation of basal PAP in the NO-treated group. A similar increase of PAP after each daily brief period of NO discontinuation has been reported in patients treated with continuous inhalation of NO for up to $53 \mathrm{~d}(19)$.

The development of hypoxic pulmonary hypertension is associated with hypertrophy and hyperplasia of smooth muscle cells in normally muscularized arteries and the appearance of new smooth muscle cells in nonmuscular and partially muscularized segments of the intraacinar circulation (27). Concomitant to the lesser degree of right ventricular hypertrophy, muscularization of distal pulmonary arteries at alveolar duct and wall levels, although still significant in comparison with the normoxic group, was less severe in hypoxic rats subjected to NO inhalation. Inhalation of NO, therefore partially prevented pulmonary vascular remodeling caused by hypoxia. It is tempting to speculate that these effects were related to the antiproliferative and antihypertrophic properties of NO. Indeed, various chemically dissimilar NO-generating vasodilators have been shown to inhibit DNA synthesis and proliferation of rat aortic muscle cells in culture (4). The ability of 8-bromo-cGMP to mimic the antimitogenic effect of NO-generating vasodilators favors the idea that this effect, similar to the relaxant action of NO, is mediated by cGMP as the second messenger. Therefore, it is possible that, in chronically hypoxic rats, inhaled NO attenuated the muscularization of pulmonary arteries by a direct inhibitory influence on smooth muscle growth. Recently, NO has been shown to inhibit hypoxia-induced expression and production of endothelin-1 and PDGF-B chain in endothelial cells (30). Since these two substances have both potent vasoconstrictor and mitogen activity, NO may also attenuate smooth muscle proliferation in response to hypoxia by interfering with endothelial production of these substances. However, in both pulmonary 
and systemic circulation, proliferation of smooth muscle may be viewed as an adaptative process in response to increased arterial wall stress. Administration of NO may mainly prevent the vasoconstrictor component of hypoxic pulmonary hypertension. Since pressure has a direct role in the remodeling of the pulmonary arterial wall during chronic hypoxia, inhaled NO may attenuate the extension of muscularization to the distal arteries by reducing the pressure. This mechanism is also suggested by the observation that various vasodilator agents acting on tone through different mechanisms, such as calcium antagonists (31), methyldopa (32), or atrial natriuretic peptide (33), have also been shown to decrease medial thickening of pulmonary arteries in chronically hypoxic rats.

It may be speculated that endothelial dysfunction represents a primary event in the pathogenesis of chronic hypoxic pulmonary hypertension. The observation that, in systemic arteries, removal of the endothelium is followed by proliferation of the underlying vascular smooth muscle cells is consistent with such a hypothesis $(34,35)$. Moreover, the present results using NO inhalation are consistent with those obtained recently in hypercholesterolemic rabbits using supplementation of dietary L-arginine to improve endothelium-dependent relaxation of systemic arteries (36). In both studies, supplying NO chronically was associated with an improvement in structural changes induced by the causal disease.

Short trials of NO inhalation have been tested recently in adult humans suffering from primary pulmonary hypertension (16) or chronic obstructive pulmonary disease (22), children with congenital heart disease (37), and neonates with persistent pulmonary hypertension $(17,18)$. However, there still remains some concern about the possible toxicity of NO, particularly when inhalation is prolonged for several days. Few patients with the adult respiratory distress syndrome have been treated with continuous inhalation of NO in a concentration of 5-20 ppm for 3-53 d. A detailed discussion of NO toxicity has been published recently (14). NO can be converted by oxidation to $\mathrm{NO}_{2} . \mathrm{NO}_{2}$ can be transformed to nitric and nitrous acids, whose toxic potential is much higher than that of $\mathrm{NO}$. $\mathrm{NO}_{2}$ at concentrations of a few parts per million induces cell alterations in the lung. In our study, the total gas flow rate of the housing chamber was maintained at high levels to minimize the contact time of $\mathrm{NO}$ with $\mathrm{O}_{2}$ and to avoid NO oxidation. Soda lime was also used to prevent $\mathrm{NO}_{2}$ accumulation in the system (38). Under these conditions, we did not measure detectable $\mathrm{NO}_{2}$ levels in the inspired or expired gas. NO combines with hemoglobin, forming $\mathrm{NO}-\mathrm{Hb}$ which is then oxidized to met-Hb in the presence of oxygen (39). Met-Hb is reduced to ferrous hemoglobin by met-Hb reductase in red blood cells. In this study, met-Hb measured in samples of arterial blood was not significantly increased. Although this study was not designed to examine the potential long-term lung toxicity of NO, we were unable to detect any evidence of toxicity by microscopic examination of the lung sections after $2 \mathrm{wk}$ of exposure to $10 \mathrm{ppm}$ NO.

In summary, the present results suggest that during exposure to chronic hypoxia, a condition associated with decreased EDRF activity and structural remodeling of the pulmonary arteries, inhaled NO exerts sustained pulmonary vasodilator effects and reduces vascular remodeling. Furthermore, in adult healthy rats, inhalation of $10 \mathrm{ppm}$ NO may be prolonged for up to $2 \mathrm{wk}$ without evidence of lung toxicity or significant increases in methemoglobinemia.

\section{Acknowledgments}

The authors thank Dr. C. Raveau from Compagnie Française des Produits Oxygénés (Meudon La Forêt, France) and M. H. Renaudin from Centre de Recherche de l'Air Liquide (Jouy en Josas, France) for helping with chemiluminescence measurements; P. Aergerter for helping with statistical analysis; and C. Brink for critical reading of the manuscript.

\section{References}

1. Palmer, R. M. J., A. G. Ferrige, and S. Moncada. 1987. Nitric oxide release accounts for the biological activity of endothelium-derived relaxing factor. Nature (Lond.). 327:524-526.

2. Ignarro, L. J., G. M. Buga, K. S. Wood, R. E. Byrns, and G. Chaudhuri 1987. Endothelium-derived relaxing factor produced and released from artery and vein is nitric oxide. Proc. Natl. Acad. Sci. USA. 84:9265-9269.

3. Ignarro, L. J., H. Lippton, J. C. Edwards, W. H. Baricos, A. L. Hyman P. J. Kadowitz, and C. A. Gruetter. 1981. Mechanism of vascular smooth muscle relaxation by organic nitrates, nitrites, nitroprusside and nitric oxide: evidence for the involvement of $S$-nitrosothiols as active intermediates. J. Pharmacol. Exp. Ther. 218:739-749.

4. Garg, U. C., and A. Hassid. 1989. Nitric oxide-generating vasodilators and 8-bromo-cyclic guanosine monophosphate inhibit mitogenesis and proliferation of cultured rat vascular smooth muscle cells. J. Clin. Invest. 83:1774-1777.

5. Dzau, V. J., and G. H. Gibbons. 1991. Endothelium and growth factors in vascular remodeling of hypertension. Hypertension (Dallas). 18:III-115-III-121.

6. Verbeuren, T. J., F. H. Jordaens, L. L. Zonnekeyn, C. E. Vanhove, M. C. Coene, and A. G. Herman. 1986. Effect of hypercholesterolemia on vascular reactivity in the rabbit. Circ. Res. 58:552-564.

7. Ludmer, P. L., A. P. Selwyn, T. L. Shook, R. R. Wayne, G. H. Mudge, R. W. Alexander, and P. Ganz. 1986. Paradoxical vasoconstriction induced by acetylcholine in atherosclerotic coronary arteries. N. Engl. J. Med. 315:10461051 .

8. Treasure, C. B., S. V. Manoukian, J. L. Klein, J. A. Vita, E. G. Nabel, G. H. Renwick, A. P. Selwyn, R. W. Alexander, and P. Ganz. 1992. Epicardial coronary artery responses to acetylcholine are impaired in hypertensive patients. Circ. Res. 71:776-780.

9. Adnot, S., B. Raffestin, S. Eddahibi, P. Braquet, and P.-E. Chabrier. 1991 Loss of endothelium-dependent relaxant activity in the pulmonary circulation of rats exposed to chronic hypoxia. J. Clin. Invest. 87:155-162.

10. Carville, C., S. Eddahibi, S. Adnot, and B. Raffestin. 1992. In vivo but not in vitro administration of $\mathrm{L}$-arginine restores EDRF activity in pulmonary arteries from chronically hypoxic rats. FASEB (Fed. Am. Soc. Exp. Biol.) J. 6:A1168. (Abstr.)

11. Dinh-Xuan, A. T., T. W. Higenbottam, C. A. Clelland, J. Pepke-Zaba, G. Cremona, A. Y. Butt, S. R. Large, F. C. Wells, and J. Wallwork. 1991. Impairment of endothelium-dependent pulmonary artery relaxation in chronic obstructive lung disease. N. Engl. J. Med. 324:1539-1547.

12. Barer, G., C. Emery, A. Stewart, D. Bee, and P. Howard. 1993. Endothelial control of the pulmonary circulation in normal and chronically hypoxic rats. $J$. Physiol. (Lond.). 463:1-16.

13. Oka, M., K. Hasunuma, S. A. Webb, T. J. Stelzner, D. M. Rodman, and I. F. McMurtry. 1993. EDRF suppresses an unidentified vasoconstrictor mechanism in hypertensive rat lungs. Am. J. Physiol. 264 (Lung Cell. Mol. Physiol. 8): L587-L597.

14. Frostell, C., M. D. Fratacci, J. C. Wain, R. Jones, and W. M. Zapol. 1991. Inhaled nitric oxide, a selective pulmonary vasodilator reversing hypoxic pulmonary vasoconstriction. Circulation. 83:2038-2047.

15. Frostell, C. G., H. Blomqvist, G. Hedenstierna, J. Lundberg, and W. M. Zapol. 1993. Inhaled nitric oxide selectively reverses human hypoxic pulmonay vasoconstriction without causing systemic vasodilation. Anesthesiology. 78:427435 .

16. Pepke-Zaba, J., T. W. Higenbottam, A. T. Dinh-Xuan, D. Stone, and J. Wallwork. 1991. Inhaled nitric oxide as a cause of selective pulmonary vasodilation in pulmonary hypertension. Lancet. 388:1173-1174.

17. Roberts, J. D., D. M. Polaner, P. Lang, and W. M. Zapol. 1992. Inhaled nitric oxide in persistent pulmonary hypertension of the newborn. Lancet. 340:818-819.

18. Kinsella, J. P., S. R. Neish, E. Schaffer, and S. H. Abman. 1992. Lowdose inhalational nitric oxide in persistent pulmonary hypertension of the newborn. Lancet. 340:819-820.

19. Rossaint, R., K. J. Falke, F. Lopez, K. Slama, U. Pison, and W. M. Zapol. 1993. Inhaled nitric oxide for the adult respiratory distress syndrome. $N$. Engl. J. Med. 328:399-405.

20. Zar, J. H. 1974. Biostatistical Analysis. Prentice Hall, Inc., Englewood Cliffs, NJ. p. 185 
21. Fratacci, M. D., C. G. Frostell, T. Y. Chen, J. C. Wain, D. R. Robinson, and W. M. Zapol. 1991. Inhaled nitric oxide: a selective pulmonary vasodilator of heparin-protamine vasoconstriction in sheep. Anesthesiology. 75:990-999.

22. Adnot, S., C. Kouyoumdjian, C. Defouilloy, P. Andrivet, C. Koumoumdjian, S. Sediame, R. Herigaut, and M. D. Fratacci. 1993. Hemodynamic and gas exchange responses to infusion of acetylcholine and inhalation of nitric oxide in patients with chronic obstructive lung disease and pulmonary hypertension. Am. Rev. Respir. Dis. 148:310-316.

23. Brashers, V. L., M. J. Peach, and C. E. Rose, Jr. 1988. Augmentation of hypoxic pulmonary vasoconstriction in the isolated perfused rat lung by in vitro antagonists of endothelium-dependent relaxation. J. Clin. Invest. 82:1495-1502.

24. Liu, S., D. E. Crawley, P. J. Barnes, and T. W. Evans. 1991. Endotheliumderived relaxing factor inhibits hypoxic pulmonary vasoconstriction in rats. Am. Rev. Respir. Dis. 143:32-37.

25. Palmer, R. M. J., D. D. Ress, D. S. Ashton, and S. Moncada. 1988. Larginine is the physiological precursor for the formation of nitric oxide in endothelium-dependent relaxation. Biochem. Biophys. Res. Commun. 153:1251-1256.

26. Eddahibi, S., S. Adnot, C. Carville, Y. Blouquit, and B. Raffestin. 1992. L-arginine restores endothelium-dependent relaxation in pulmonary circulation of chronically hypoxic rats. Am. J. Physiol. 263:L194-L200.

27. Rabinovitch, M., W. Gamble, A. S. Nadas, O. Miettinen, and L. Reid. 1979. Rat pulmonary circulation after chronic hypoxia: hemodynamic and structural features. Am. J. Physiol. 236:818-827.

28. Fried, R., B. Meyrick, M. Rabinovitch, and L. Reid. 1983. Polycythemia and the acute hypoxic response in awake rats following chronic hypoxia. J. Appl. Physiol. Respir. Environ. Exercise Physiol. 55:1167-1172.

29. Fried, R., and L. M. Reid. 1984. Early recovery from hypoxic pulmonary hypertension: a structural and functional study. J. Appl. Physiol. Respir. Environ. Exercise Physiol. 57:1247-1253.
30. Kourembanas, S., L. P. McQuillan, G. K. Leung, and D. V. Faller. 1993. Nitric oxide regulates the expression of vasoconstrictors and growth factors by vascular endothelium under both normoxia and hypoxia. J. Clin. Invest. 92:99104.

31. Stanbrook, H. S., K. G. Morris, and I. F. McMurtry. 1984. Prevention and reversal of hypoxic pulmonary hypertension by calcium antagonists. Am. Rev. Respir. Dis. 130:81-85.

32. Suggett, A. J., and J. Herget. 1977. Effect of $\alpha$-methyldopa on the pulmonary vascular changes induced by chronic hypoxia in rats. Clin. Sci. Mol. Med. 53:397-400.

33. Jin, H., R.-H. Yang, Y.-F. Chen, R. M. Jackson, and S. Oparil. 1990. Atrial natriuretic peptide attenuates the development of pulmonary hypertension in rats adapted to chronic hypoxia. J. Clin. Invest. 85:115-120.

34. Clowes, A. W., M. A. Reidy, and M. M. Clowes. 1983. Kinetics of cellular proliferation after arterial injury. I. Smooth muscle growth in the absence of endothelium. Lab. Invest. 49:327-333.

35. Goldberg, I. D., M. B. Stermerman, B. J. Ransil, and R. L. Fuhro. 1980 In vivo aortic muscle cell growth kinetics: differences between thoracic and abdominal segments after intimal injury in the rabbit. Circ. Res. 47:182-189.

36. Cooke, J. P., A. H. Singer, P. Tsao, P. Zera, R. A. Rowan, and M. E. Billingham. 1992. Antiatherogenic effects of L-arginine in the hypercholesterolemic rabbit. J. Clin. Invest. 90:1168-1172.

37. Roberts, J. D., P. Lang, L. M. Bigatello, G. J. Vlahakes, and W. M. Zapol. 1993. Inhaled nitric oxide in congenital heart disease. Circulation. 87:447-453.

38. Oda, H., S. Kusumoto, and T. Nakajima. 1975. Nitrosyl-hemoglobin formation in the blood of animals exposed to nitric oxide. Arch. Environ. Health. 30:453-456.

39. Chiodi, H., and J. G. Mohler. 1985. Effects of exposure of blood hemoglobin to nitric oxide. Environ. Res. 37:355-363. 